\title{
Transurethral mesh resection after urethral erosion of tension-free vaginal tape: report of three cases and review of literature
}

\author{
S. A. M. Wijffels $\cdot$ H. W. Elzevier • \\ A. A. B. Lycklama a Nijeholt
}

Received: 7 July 2008 / Accepted: 30 July 2008 / Published online: 21 August 2008

(C) The Author(s) 2008. This article is published with open access at Springerlink.com

\begin{abstract}
A rare complication after tension-free vaginal tape (TVT; including TVT-O) procedure is erosion of the tape through the urethral wall. In the literature, different methods to remove this intra-urethral tape are described. Most authors used the transvaginal approach with urethrotomy. In the cases described in this article, the transurethral approach is applied and proposed as the optimal method, being minimally invasive and less damaging to the urethral wall A transurethral catheter can be removed shortly after surgery to enable optimal tissue healing of the urethral mucosa.
\end{abstract}

Keywords TVT · Urethral erosion · Tape erosion ·

Complications

\section{Introduction}

In the treatment of women with urinary stress incontinence, the tension-free vaginal tape (TVT) procedure is a popular operation today. In this procedure, a tension-free Prolene tape is placed suburethrally. This minimal invasive method combines rapid recovery with good results. Also, the number of complications is low. A rare complication after this procedure is urethral erosion of the tape. In the literature, different procedures are described to clear the urethra of this tape [1-5], often by transvaginal approach and one by laparoscopy (Table 1).

S. A. M. Wijffels $(\bowtie) \cdot H$. W. Elzevier

A. A. B. Lycklama a Nijeholt

Department of Urology, Leiden University Medical Centre,

Postbus 9600,

2300 RC Leiden, the Netherlands

e-mail: Stefanie_wijffels@hotmail.com
In this article, we describe three cases of a transurethral resection of the intra-urethral part of the tape and give an overview of approaches to remove eroded tension-free vaginal tapes.

\section{Cases}

\section{Case 1}

A 54-year-old woman underwent a standard TVT procedure because of stress urinary incontinence. After the operation, she presented with recurrent urinary tract infections (UTIs). A urethrocystoscopy with a $0^{\circ}$ vision was performed and the tape was seen midurethral at the dorsal side (Fig. 1).

Surgical removal under regional anesthesia in lithotomy position included localising the mesh with a urethrocystoscope with $12^{\circ}$ vision. The tape was grasped with a forceps next to the right side of the urethral wall inside the urethra. With gentle traction on the forceps, the mesh was cut blindly transurethrally with scissors. The same procedure was done on the left side inside the urethra. The mesh, covered with encrustations, was removed transurethrally. On urethrocystoscopy, the urethral mucosa was somewhat damaged and a cut edge of the tape was seen within the damaged mucosa.

The procedure took $30 \mathrm{~min}$.

The transurethral catheter was removed 1 week postoperatively. Because of persistent complaints of urgency and UTI, a urethrocystoscopy was performed 6 weeks after operation. A cut edge of tape was still seen in the urethra and removed using the same technique under anaesthesia. After operation, the catheter was removed a few hours after the procedure. Afterwards, the patient recovered without any complaints including incontinence. A few months after 
Table 1 Studies in which mesh erosion is described and their method of removal

\begin{tabular}{lll}
\hline References & Year of publication & Management \\
\hline Koelbl et al. & 2001 & Transvaginal approach with urethrotomy \\
Madjar et al & 2002 & Transurethral resection with transvaginal approach and urethrotomy \\
Werner et al. & 2003 & Transurethral resection \\
McLennan & 2004 & Transurethral resection \\
Rehman et al. & 2008 & Extraperitoneal laparoscopy \\
\hline
\end{tabular}

the procedure on urethrocystoscopy, no tape remnants were seen.

\section{Case 2}

After a standard TVT procedure, a 44-year-old patient complained of recurrent UTIs and urge urinary incontinence. On urethrocystoscopy 14 months after operation, the tape was seen in the urethra. The tape was removed under regional anaesthesia as described before. The procedure took $25 \mathrm{~min}$. The indwelling catheter was removed the same day. Afterwards, there were no complaints including incontinence and 3 months after the procedure no tape remnants were seen in the urethra on urethrocystoscopy.

\section{Case 3}

A 59-year-old woman presented 6 months after a tensionfree vaginal obturator tape procedure with complaints of combined urge and stress urinary incontinence who was initially dry after the procedure. On urethrocystoscopy, the tape was seen, eroded through the urethral wall.

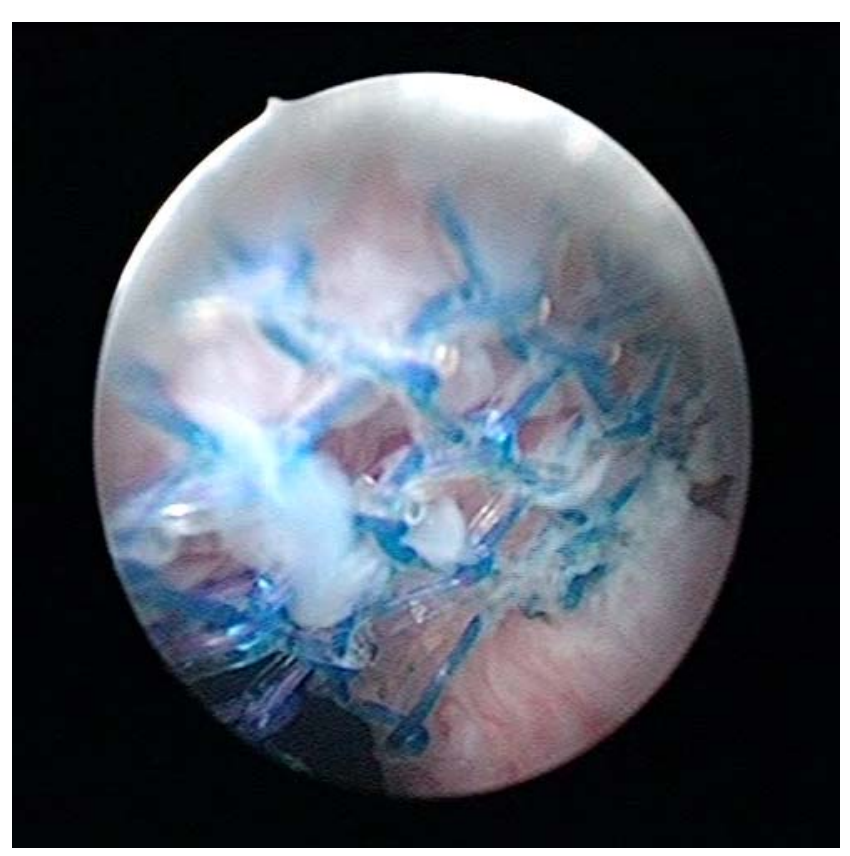

Fig. 1 Mesh eroded through urethral wall
The tape was removed as described above. The procedure took $30 \mathrm{~min}$. A transurethral catheter was left in place for a few hours and the patient was dismissed the same day.

Two months after surgery, a complete removal of the mesh was assessed on urethrocystoscopy. No scars of the surgery or mesh particles were seen in the urethral wall. Symptoms of urge urinary incontinence disappeared. A redo TVT procedure because of persistent stress incontinence was performed with good result.

\section{Discussion}

Erosion of the mesh through the urethral wall is a rare complication of a TVT procedure for stress urinary incontinence. Various methods to remove the mesh are described in the literature (Table 1).

Werner et al. [1] and McLennan [2] described removal of an eroded mesh transurethrally, as described in the cases in this report. Koelbl et al. [3] used the transvaginal method with urethrotomy, a tissue-damaging approach. Madjar et al. [4] removed the tape transurethrally but because of persistent intra-urethral tape remnants they performed a urethrotomy with transvaginal approach to remove the tape remnants.

Werner et al. and McLennan both removed the mesh transurethrally using a hysteroscope to allow optimal visualisation. After resection, Werner et al. used a suprapubic catheter and McLennan a transurethral catheter, both for 3 days.

Rehman et al. [5] removed a urethral sling by extraperitoneal laparoscopy with opening of the bladder. An indwelling catheter was left in for 1 week. This method is less invasive compared with the transvaginal approach. This procedure took $75 \mathrm{~min}$ at least, twice as much as needed in the transurethral resection.

In our three cases, the first patient had an indwelling catheter for 1 week. After removal, the patient still had complaints and the rest of the mesh was still seen on urethroscopy. This is in contrast with the other two patients in whom the catheter was removed the same day and who did not have complaints afterwards. Late removal of the indwelling catheter may impair mucosal healing and hence 
promote persistence of tape edges through the urethral wall. The use of a hysteroscope appeared not to be necessary in our three patients. After cutting the tape blindly with scissors, in combination with gentle traction using a forceps, no evident urethral wall damage was seen.

The transurethral method is, in comparison with the transvaginal approach, minimally invasive. Because no dissection is performed, healing of urethral tissue is optimal.

In conclusion, the transurethral method to remove through the urethral wall eroded tension-free vaginal tapes without dissection is potentially less harmful for the urethra. In addition, it seems better to remove the catheter a few hours after surgery for optimal tissue healing. The minimal invasiveness of transurethral excision of the tape is an important advantage of this technique and hence this method should be applied before using more invasive surgery.

\section{Conflicts of interest None.}

Open Access This article is distributed under the terms of the Creative Commons Attribution Noncommercial License which permits any noncommercial use, distribution, and reproduction in any medium, provided the original author(s) and source are credited.

\section{References}

1. Werner M, Najjari L, Schuessler B (2003) Transurethral resection of tension-free vaginal tape penetrating the urethra. Obstet Gynecol 102(5):1034-1036

2. McLennan MT (2004) Transurethral resection of transvaginal tape. Int Urogynecol J Pelvic Floor Dysfunct 15(5):360-362

3. Koelbl H, Stoerer S, Seliger G, Wolters M (2001) Transurethral penetration of a tension-free vaginal tape. BJOG 108(7):763-765

4. Madjar S, Tchetgen MB, Van Antwerp A, Abdelmalak J, Rackley R (2002) Urethral erosion of tension-free vaginal tape. Urology 59 (4):601

5. Rehman J, Chugtai B, Sukkarich T, Khan A (2008) Extraperitoneal laparoscopic removal of eroded midurethral sling: a new technique. J Endourol 22(2):365-368 